\title{
RADIATION-INDUCED GYNOGENESIS AND ANDROGENESIS IN FISH
}

\author{
C. E. PURDOM \\ Ministry of Agriculture, Fisheries and Food, Fisheries Laboratory, Lowestoft, England.
}

Received 7.xi.68

\section{INTRODUGTION}

GurRent ideas on fish farming have stimulated interest in fish genetics and highlighted the need for more genetic analysis, particularly of fish of commercial importance. A major difficulty in breeding fish of commercial interest is the long generation time of 3 years or more. The work reported here is an investigation of the possibility of producing homozygous clones of fish rapidly by gynogenesis-a special form of artificial parthenogenesis in which activation of the eggs is achieved by fertilisation with genetically inert spermatozoa.

Gynogenesis was first observed in frogs by Hertwig (1911), who showed that a low frequency of apparently normal embryos appeared when eggs were fertilised by spermatozoa which had received radium gamma ray doses much higher than levels normally required to produce 100 per cent. abnormality. It was concluded that, at these very high doses, the genetic material of the spermatozoa was so thoroughly destroyed that it played no part in the subsequent parthenogenetic development of the egg. This "Hertwig effect" has been confirmed several times in amphibia (reviewed by Beatty, 1964), and, as in other forms of parthenogenesis in vertebrates, the resulting parthenogenomes are usually haploid, and although developing normally at first are grossly abnormal at hatching. However, sporadic occurrences of more normal hatchlings have been observed following parthenogenesis by pricking and these have been shown to be diploid (Parmenter, 1933; Kawamura, 1939).

Several mechanisms have been proposed to explain the process of diploidisation (see Tyler, 1941; Beatty, 1964), but the experimental evidence in amphibia seems to favour diploidisation by doubling of the haploid female genome during cleavage. Thus Parmenter (1933) and Kawamura (1939) observed delayed cleavage in parthenogenetic eggs which subsequently produced diploid organisms, and Subtelny (1958) produced diploid individuals following transplantation of haploid nuclei into enucleated eggs, i.e. diploidisation in the absence of polar bodies.

Increased frequencies of both haploid and diploid gynogenomes have been reported by Rostand (1934, 1936) following post-fertilisation cold treatments of amphibian eggs; gynogenesis was produced by irradiated spermatozoa and also by fertilisation of eggs with foreign spermatozoa (" false hybrids").

Gynogenesis is a natural form of reproduction in the teleost Mollienesia formosa (Hubbs and Hubbs, 1932), and the existence of distinct clones in laboratory fish has been demonstrated by tissue transplantation tests (Kallman, 1962). Perfectly normal and fully viable broods can easily be reared, and this suggests that diploidy is retained through suppression of meiosis Kallman, loc. cit.) leading to fixed heterozygosity.

Recent work in Russia (Romashov, Belyaeva, Golovinskaia and Pro- 
kofeva-Bel'govskaya, 1961) has shown that radiation-induced gynogenesis also occurs in fish. Low frequencies of diploid individuals were obtained from eggs of carp, sturgeon and loach fertilised by spermatozoa given X-ray doses in excess of 100000 roentgen. It was also found that cold shocks applied shortly after fertilisation greatly increased this frequency. The present paper describes studies on the production of gynogenetic offspring in some marine fish and in trout, with special reference to the viability of diploid gynogenomes and the mode of diploidisation.

\section{Materials AND methods}

Experiments were performed at Lowestoft with plaice (Pleuronectes platessa L.) and flounder (Platichthys flesus L.) caught in the North Sea, and at a Berkshire trout farm with brown trout (Salmo trutta L.).

The original numbering of experiments is retained in the results section, and abortive or inconclusive experiments are omitted. The gynogenesis experiments are prefixed with the letter $\mathrm{G}$ and the androgenesis experiments with the letter A.

For gynogenesis experiments, milt was stripped from ripe male fish and some was exposed to cobalt-60 gamma irradiation with doses of between $10^{4}$ and $10^{5} \mathrm{rad}$, the rest being used as the control. Dose rates were approximately $7 \times 10^{5} \mathrm{rad} /$ hour in experiments up to $\mathrm{G} 8$ and $2 \times 10^{4} \mathrm{rad} /$ hour thereafter and in all androgenesis experiments. The irradiated and the control milts were both kept at $0^{\circ} \mathrm{C}$. during the time from stripping to fertilisation. Artificial fertilisation was carried out by mixing milt with eggs stripped into a small amount of water at $8^{\circ} \mathrm{C}$. for plaice, $11^{\circ} \mathrm{C}$. for flounder and $10^{\circ} \mathrm{C}$. for trout. In the plaice and flounder experiments cold shocks were applied to a sample of the fertilised eggs by dividing the eggs into two groups, one of which was topped up with water at the temperatures stated above, the other with water at $-1.7^{\circ} \mathrm{C}$. to produce final temperatures of between $0^{\circ} \mathrm{C}$. and $1^{\circ} \mathrm{C}$. These cold shocks were applied 20 minutes after fertilisation and maintained for 3 hours in a $0^{\circ} \mathrm{C}$. enclosure, after which the egg containers were allowed to regain their former temperatures. Cold shocks were not used in the experiments with trout, since facilities were not available.

For androgenesis experiments in plaice and flounder, the process was repeated, irradiating the eggs instead of the milt. In these experiments, several hours elapsed between the stripping of the eggs and fertilisation, but in preliminary trials it was found that eggs remained viable when stored at $0^{\circ} \mathrm{C}$. for periods of up to 24 hours.

Plaice and flounder eggs are buoyant while alive but sink when dead; dead eggs were therefore collected daily in these experiments and countedvolumetrically with the larger samples-and examined for stage of development at death. In the trout experiments, dead eggs were picked out by hand, and only a very approximate record of mortality rates was possible, because of the uncertain criteria of death. Live or moribund material was fixed in Bouin at various stages of the experiments for sectioning and staining with haematoxylin for cytological examination.

\section{Results}

Artificial fertilisation is an uncertain process, particularly in marine fish, and several of the experiments performed during the 1967 and 1968 spawning 
seasons were unsuccessful because either the eggs were under- or over-ripe, or the spermatozoa non-viable. In all the experiments in which the control fertilisation showed that the eggs and milt were ripe, radiation treatment of spermatozoa or eggs had no apparent effect on the process of fertilisation or on the early cleavage of the fertilised egg. Even after an extreme treatment of $67000 \mathrm{rad}$, both to the eggs and the spermatozoa of plaice or flounder, early cleavage appeared normal. Similar autonomy of early cleavage stages is well known in amphibia.

\section{(i) Gynogenesis}

Survival curves for plaice eggs fertilised with irradiated or control unirradiated spermatozoa are shown in figs. 1 and 2. Three radiation doses $\left(10^{4}, 5 \times 10^{4}\right.$ and $\left.10^{5} \mathrm{rad}\right)$ were used, and in all cases, including the controls,

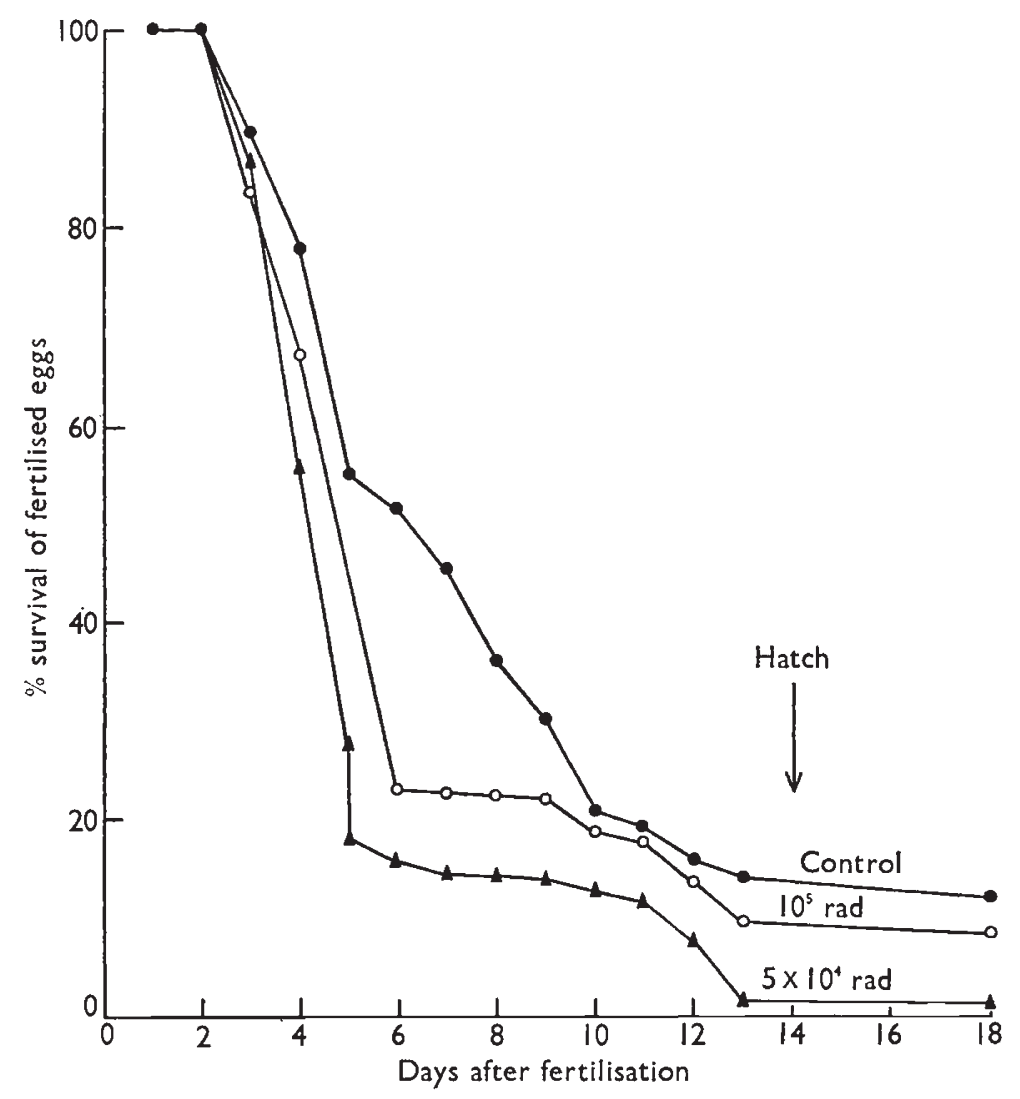

FIG. 1.-Survival curves for fertilised plaice eggs, in experiment G6.

a cold shock was applied to the fertilised eggs. All the curves show a typical early pattern of very little death during the first 2 or 3 days after fertilisation, followed in the next 2-3 days by heavy mortalities which appeared to occur at the time of gastrulation. The control groups also showed this early mortality but to a much lower degree than the eggs fertilised with irradiated 
spermatozoa. After gastrulation, mortality rates remained low up to the time of normal hatching, 15-16 days after fertilisation.

Within the irradiated groups, it can be seen that the severity of the effect was inversely related to the dose (table 1 ). Thus at the lowest dose of $10^{4} \mathrm{rad}$, in experiment G6, over 98 per cent. of the fertile eggs were dead 6 days after fertilisation and 100 per cent. by the eleventh day. In the same experiment,

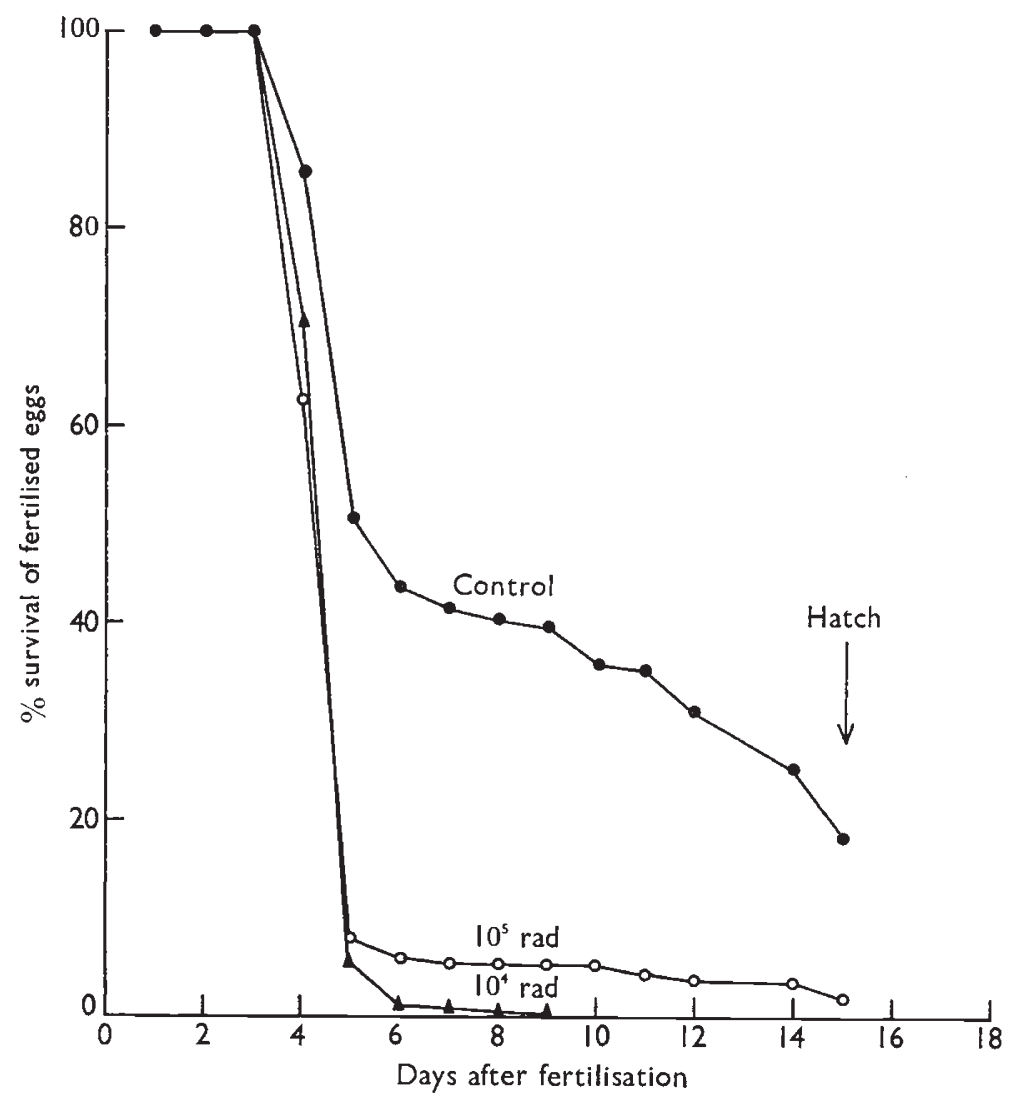

Fug. 2.-Survival curves for fertilised plaice eggs, in experiment G11.

TARLE 1

Survival of plaice eggs to 6 days after fertilisation and to hatching, in experiments $G 6$ and $G 11$

\begin{tabular}{|c|c|c|c|c|c|c|}
\hline \multirow[b]{2}{*}{$\begin{array}{c}\text { Dose in } \\
\text { rad }\end{array}$} & \multirow[b]{2}{*}{ Experiment } & \multirow[b]{2}{*}{$\begin{array}{l}\text { Number of } \\
\text { fertile eggs }\end{array}$} & \multicolumn{2}{|c|}{$\begin{array}{c}\text { Survival at } \\
6 \text { days }\end{array}$} & \multicolumn{2}{|c|}{ Hatching } \\
\hline & & & No. & $\%$ & No. & $\%$ \\
\hline Control & G6 & 5200 & 2680 & $51 \cdot 5$ & 725 & $14 \cdot 0$ \\
\hline Control & G11 & 498 & 217 & $43 \cdot 5$ & 90 & $18 \cdot 1$ \\
\hline $10^{4}$ & G11 & 679 & 9 & $1 \cdot 3$ & 0 & $0 \cdot 0$ \\
\hline $5 \times 10^{4}$ & G6 & 5030 & 790 & 15.9 & 86 & 1.6 \\
\hline $10^{5}$ & G6 & 4220 & 970 & 23.0 & 400 & $9 \cdot 5$ \\
\hline $10^{5}$ & G11 & 512 & 29 & $5 \cdot 7$ & 9 & 1.8 \\
\hline
\end{tabular}


at $5 \times 10^{4} \mathrm{rad}, 15.9$ per cent. of the eggs survived for 6 days but only 1.6 per cent. to hatching; at $10^{5}$ rad survival was 23.0 per cent. at 6 days and 9.5 per cent. at hatching. In experiment G11 survival levels after $10^{5} \mathrm{rad}$ were lower than in G6 at this rate, but still higher than the contemporaneous group at $10^{4} \mathrm{rad}$.

TABLE 2

Approximate percentage survival in trout eggs fertilised with irradiated or control spermatozoa (experiment G8)

$\begin{array}{cccc}\begin{array}{c}\text { Weeks after } \\ \text { fertilisation }\end{array} & \begin{array}{c}\text { Control } \\ \text { (approx. 2000 eggs) }\end{array} & \begin{array}{c}10^{4} \mathrm{rad} \\ \text { (approx. 2000 eggs) }\end{array} & \begin{array}{c}10^{5} \mathrm{rad} \\ \text { (approx. 20,000 eggs) }\end{array} \\ 4 & 95 & 0 \cdot 0 & 50 \\ 5 & 95 & - & 20 \\ 6 & 90 & - & 5 \\ 10 & 90 & - & 2\end{array}$

Similar results were observed in experiment G8, with trout (table 2). All the eggs fertilised with spermatozoa exposed to $10^{4} \mathrm{rad}$ were dead 4 weeks after fertilisation, compared with approximately 20 per cent. survival in the $10^{5}$ rad group and 95 per cent. in the unirradiated controls. Very few further deaths occurred in the controls through hatching and up to the time the alevins began to feed, 10 weeks after fertilisation. In most of the surviving eggs of the $10^{5}$ rad groups at 5 weeks the embryos were grossly abnormal and died at about the time of hatching, 6 weeks after fertilisation, but 35 nearnormal alevins were alive and feeding 10 weeks after fertilisation.

These results demonstrate conclusively the presence of a "Hertwig effect" in plaice and trout, i.e. a lowering of the harmful effects of radiation to spermatozoa with increasing dose, presumably arising from the gynogenetic development of the fertilised eggs at high doses.

TABle 3

Mean diameters (in drum-micrometer units) of cartilage cell nuclei of normal and gynogenetic trout

\begin{tabular}{lccc} 
& \multicolumn{2}{c}{ Gynogenetic fish } \\
& Control fish & Near normal & Abnormal \\
$\begin{array}{l}\text { Mean size } \pm 2 \sigma \\
\text { Calculated nuclear } \\
\text { vol. in units }\end{array}$ & $24.5 \pm 5.00$ & $24.0 \pm 4.00$ & $19.9 \pm 3.40$ \\
& $3.1 \times 10^{4}$ & $3.0 \times 10^{4}$ & $1.6 \times 10^{4}$
\end{tabular}

\section{(ii) Haploids and diploids}

Embryos which survived to a late stage could be classified into two types corresponding very closely to the haploid and diploid syndromes described in parthenogenetic frogs. The haploid types (plate $\mathrm{G}$ and $\mathrm{F}$ ) were grossly abnormal, showing in particular short thick bodies with poorly developed tails and usually with small underdeveloped eyes; these individuals rarely hatched and never began to feed.

Chromosome counts were not possible in sectioned preserved material, due to the absence of appropriate cells in division. Measurement of nuclear size, however, confirmed the haploidy of the grossly abnormal gynogenomes and the diploidy of the near-normal ones. Table 3 lists the mean diameters 
of cartilage cell nuclei of trout alevins at hatching. No difference was observed between a control fish and a near-normal gynogenome $(t=0.71 ; \mathrm{P}=0.5)$, but in a grossly abnormal alevin the nuclear diameter was significantly lower than in the control $(t=6.88 ; \mathrm{P}<0.001)$ or in the near-normal gynogenome $(t=7 \cdot 25 ; \mathrm{P}<0.001)$. The ratio between the calculated volumes of nuclei of the haploid type and the diploid types was approximately 0.5 , which agrees with the expectation that nuclear volume is proportional to ploidy-as observed in heteroploid amphibia (Fankhauser, 1945).

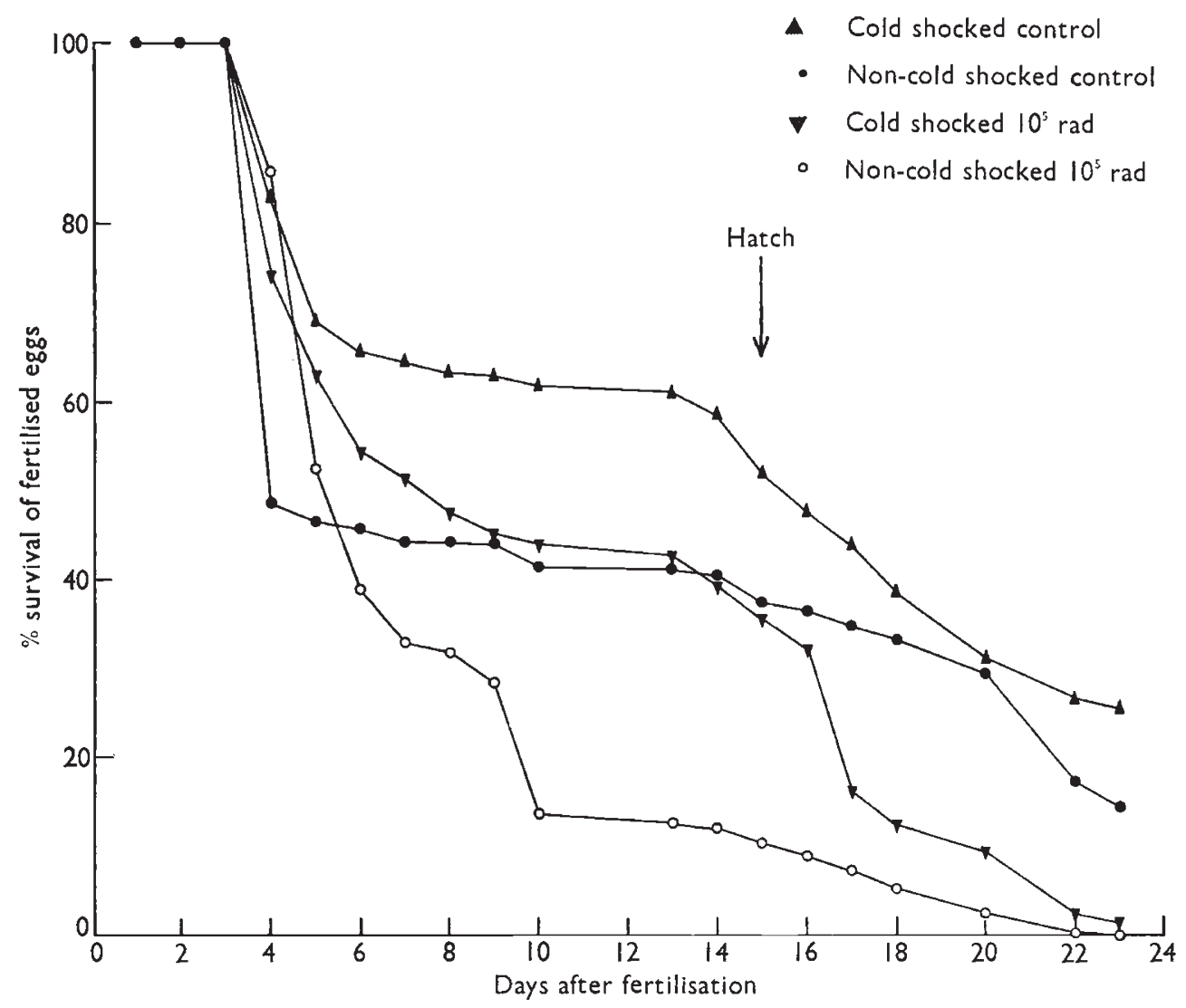

FIG. 3.-Survival curves for fertilised plaice eggs, in experiment G15.

(iii) Cold shocks

The effect of a cold shock also shows parallelism with parthenogenesis in amphibia and radiation gynogenesis in the loach, Misgurnus fossilis. The results of experiment G15, showing the survival of plaice eggs with and without a cold shock after fertilisation by control spermatozoa or spermatozoa exposed to $10^{5} \mathrm{rad}$, are plotted in fig. 3. In the control eggs early mortality was less severe in the cold-shocked group than in those not exposed to a cold shock, but this phenomenon was not observed in two earlier experiments and cannot be explained. In the irradiated groups, the cold-shocked series showed a high survival rate not very much below that of the controls up to 
the time of hatching, whereas the non-cold-shocked eggs died rapidly through the time up to normal hatching. In addition, the embryos of the non-coldshocked series were almost all of the haploid type, but in the cold-shocked series most of the embryos were of the diploid type (table 4). Haploid types were not observed amongst the controls, whether cold-shocked or not. The effect of a post-fertilisation cold shock in increasing the frequency of diploid radiation gynogenesis is therefore confirmed.

\section{TABLE 4}

Mortality of diploid and haploid gynogenomes in cold-shocked and non-cold-shocked eggs in experiment 615

\begin{tabular}{ccccc}
$\begin{array}{c}\text { Days after } \\
\text { fertilisation }\end{array}$ & $\overbrace{\begin{array}{c}\text { Number of } \\
\text { Haploids }\end{array}}^{\text {Non-cold-shocked eggs }}$ & Diploids & & \multicolumn{2}{c}{$\begin{array}{c}\text { Number of } \\
\text { Haploids }\end{array}$} & Diploids \\
13 & 80 & - & 21 & 73 \\
14 & 38 & - & 7 & 180 \\
15 & 110 & - & 11 & 187 \\
16 & 89 & - & 20 & 176 \\
17 & 123 & - & 36 & 868 \\
18 & 134 & - & 5 & 204 \\
20 & 178 & - & 2 & 163 \\
22 & 155 & - & - & 395 \\
23 & - & - & - & 41 \\
27 & - & - & - & 34
\end{tabular}

\section{(iv) Viability}

That the haploids were much less viable than the diploids is apparent from fig. 3 and table 4 . In plaice, haploid development was largely arrested at about 7 days after fertilisation and, although some embryos survived beyond the normal time of hatching of the controls, they mostly failed to hatch, or died during the first day after hatching.

Fig. 4 compares the survival of control diploids (CG) and gynogenetic diploids $(\mathrm{RG})$ obtained by subtracting the number of haploids from group $\mathrm{RC}$ of experiment G15. From the point where a distinction was drawn between haploids and diploids, 12 days after fertilisation, the mortality amongst the gynogenetic diploids was similar to that in the controls up to the time of hatching; after this, mortality in the gynogenetic diploids was much greater than amongst the controls. The diploid gynogenetic plaice also showed a high frequency of minor abnormalities, particularly slight body flexions, when compared with the controls. These abnormalities closely resemble the effects observed in highly inbred aquarium fish.

Plaice gynogenomes were reared to feeding stages in several experiments, but in only one were they reared to metamorphosis. In this experiment (G6) six metamorphosed gynogenomes were reared to an age of 11 weeks, but they then died, along with all the controls, possibly due to a ciliate infestation. Lengths of the metamorphosed gynogenomes and some of the controls are shown in table 5; on average, the gynogenomes were smaller than the controls, but the difference was only just significant on a one-tailed test $(t=1 \cdot 836 ; \mathrm{P}=0 \cdot 05)$.

2 E 2 


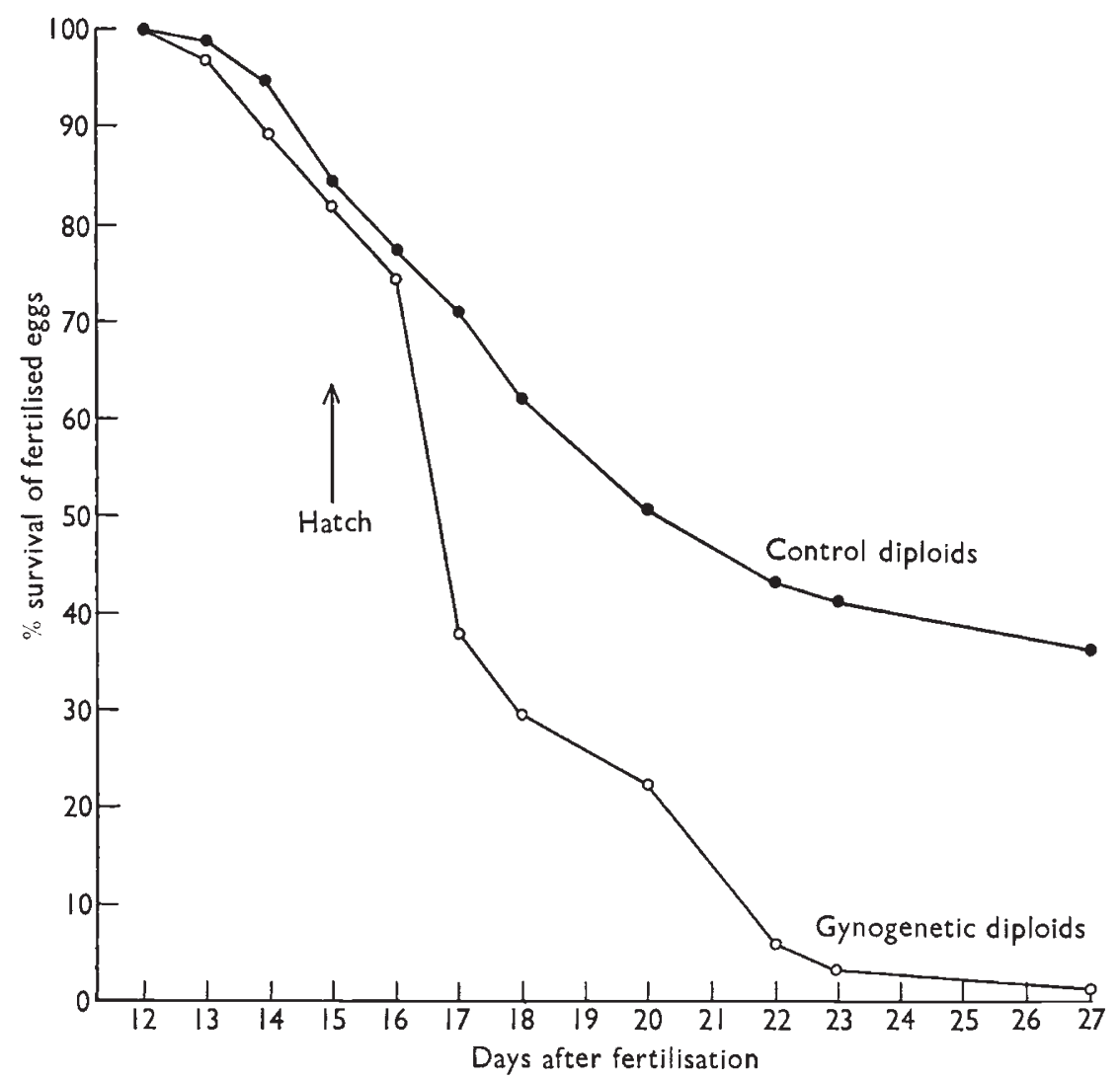

FIG. 4.-A comparison of the survival of diploid gynogenetic and control plaice, in experiment G15.

Gynogenetic trout also showed slightly bent or twisted bodies, absent among the controls (plate B), and when both groups were transferred from running water troughs in the trout hatchery to semi-static laboratory conditions, all the gynogenetic fish died, whilst all but a few of the more numerous, and much more densely crowded, controls survived this treatment.

\section{TABLE 5}

Lengths of six 11-week-old gynogenetic and five control plaice (experiment G6)

\section{length in $\mathrm{cm}$.}

Diploid gynogenomes

Diploid controls
$1 \cdot 2,1 \cdot 0,1 \cdot 0,1 \cdot 0,0 \cdot 9,0 \cdot 9,0 \cdot 7$

$1 \cdot 3,1 \cdot 2,1 \cdot 1,1 \cdot 0,0 \cdot 9$
Mean $\pm 2 \sigma$

$0 \cdot 95 \pm 0 \cdot 28$

$1 \cdot 12 \pm 0 \cdot 28$

\section{(v) Cleavage}

The nature of diploidisation in parthenogenetic systems and the effect of a cold shock in promoting the process are not fully understood, although in frogs duplication of a haploid chromosome set by mitosis seems well established. To investigate these processes further in fish, experiments were performed in which the cold shock was applied at 20 or 40 minutes after 
fertilisation, followed by observation of cleavage in live eggs to determine whether or not a delay occurred, as in frog diploid parthenogenesis. In one series of tests in experiment G18, plaice eggs fertilised by normal spermatozoa were either left at their normal temperature $(\mathrm{CH})$, or cold-shocked, either from 20 minutes after fertilisation (CG1), or from 40 minutes after fertilisation (CC2). A similar series (RH, RCl and RC2) was run with eggs fertilised by spermatozoa exposed to $10^{5}$ rad gamma rays. At 4 hours 45 minutes after fertilisation, the $\mathrm{CH}$ and $\mathrm{RH}$ eggs were both in the 2-cell stage, first cleavage having been completed; at 6 hours 30 minutes after fertilisation, these eggs were in the 4-cell stage, whilst all the others were in the 2-cell stage. On completion of development, almost all the survivors in the control series and in RCl were of the normal diploid type (plate, D and E), whilst

TABLE 6

Percentage of fertile flounder eggs completing first cleavage at successive times after fertilisation in experiment $G 21$ (initial numbers of eggs in parentheses)

$\begin{array}{cccc}\begin{array}{c}\text { Time after } \\ \text { fertilisation } \\ \text { hr. }\end{array} & \text { min. } & \begin{array}{c}\text { Control eggs } \\ \text { (no cold shock) } \\ \text { Series* }\end{array} \\ & & & \text { R } \\ 2 & 15 & -62) & (94) \\ 2 & 30 & 80 & 80 \\ 2 & 45 & 100 & 100 \\ 4 & 45 & & \\ 5 & 00 & & \\ 5 & 15 & & \\ 5 & 30 & & \\ 5 & 45 & & \end{array}$

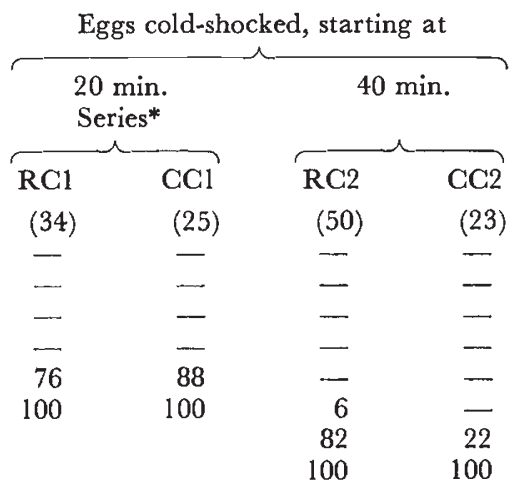

* All R series: spermatozoa irradiated with $10^{5} \mathrm{rad}$. All C series: spermatozoa unirradiated.

in $\mathrm{RH}$ and $\mathrm{RC} 2$ the embryos were predominantly haploid. A similar experiment was performed using flounder eggs (experiment G21), but with the exception that the eggs were examined every 15 minutes during the first 8 hours after fertilisation. Experiment G21 fully confirmed the results of G18; all the controls and most of the RCl eggs developed as diploids, whilst the $\mathrm{RH}$ and RC2 embryos were predominantly haploid. Table 6 summarises the timing of cleavage in the six groups. Delayed cleavage arose as a result of the cold shocks, but there was no difference between the irradiated and control eggs at each of the temperature regimes; more specifically, diploidisation in group $\mathrm{RCl}$ was not associated with delay other than that which could be attributed to the general effect of the cold shock as observed in CCl (diploid controls) and RC2 (haploid gynogenomes).

\section{(vi) Androgenesis}

Experiments were performed to explore the possibility of androgenesis in fish and to see whether or not diploid individuals could be produced as in diploid radiation gynogenesis. Following irradiation at doses from $10^{4}$ to $10^{5} \mathrm{rad}$, eggs cleaved normally when fertilised by unirradiated sperma- 
tozoa. No "Hertwig effect" was observed when flounder eggs were irradiated over a range from $10^{4}$ to $9 \times 10^{4} \mathrm{rad}$ (experiment A5), but the great majority of eggs, even in the controls, were infertile, and this result was therefore not conclusive. In a further experiment (A6), flounder eggs exposed to $6 \cdot 7 \times 10^{4} \mathrm{rad}$ and fertilised by normal spermatozoa produced large numbers of late embryos which were all of the typical haploid type and indistinguishable from the haploid types produced by gynogenesis. It seems unlikely that the egg nuclear material could survive a radiation dose of $6 \cdot 7 \times$ $10^{4} \mathrm{rad}$ and it must therefore be concluded that these haploids were androgenetic. Cold shocks were applied to the fertilised eggs in experiment A6 but no diploid types were found in the irradiated series. Diploidisation by doubling of a haploid set of paternal chromosomes during first cleavage, similar to the phenomenon observed by Subtelny (1958) in frogs, was not observed in fish.

\section{Discussion and conclusions}

The results of experiments with plaice, flounder and trout show that embryonic development occurs in eggs fertilised by spermatozoa which were exposed to radiation doses ranging from $10^{4}$ to $10^{5} \mathrm{rad}$, and that viability is highest following the higher radiation doses. This demonstrates the existence of a "Hertwig effect" in these fish and confirms the similar findings by Romashov et al. (1961) in loach, carp and sturgeon. Hertwig's conclusions (1911) that this paradoxical effect in amphibia arose through the complete de-activation of the genetic material of the spermatozoa at high radiation doses, followed by gynogenetic development of the fertilised egg, also seems valid for fish. Thus Romashov et al. (loc. cit.) were unable to detect any paternal effects in species crosses using irradiated spermatozoa, and similar observations were made in the present study with flounder/plaice "false hybrids" in which the irradiated series were more viable and more normal than the controls!

Gynogenesis was also indicated by the preponderance of haploid type embryos and the sporadic appearance of more normal diploid types following high radiation doses to spermatozoa. Haploidy was demonstrated by chromosome counts in early blastomeres by Romashov et al. (loc. cit.), but in the present study suitable cell division stages could not be found in preserved material. Nevertheless, the close parallelism between the appearances of the " haploid types" and the occasional " diploid types" with known haploid and diploid syndromes in frogs, as described by Miyada (1960), together with the evidence of small nuclear size in " haploid type" trout gynogenomes, leaves little doubt that the grossly abnormal embryos were haploid. That the occasional diploid individuals arose by diploid gynogenesis and not through chance survival of irradiated spermatozoa is demonstrated by the greatly increased frequency of diploids following cold shocks to the fertilised eggs.

There are several possible mechanisms by which diploidy could be reestablished during parthenogenesis. Reviews by Tyler (1941) and Beatty (1964) list three basic categories for diploid $F_{0}$ females: (1) retention of a first polar body, (2) retention of a second polar body, (3) regulation during cleavage mitoses. Each of these consequences would lead to a level of inbreeding greater than could normally be obtained by full-sib mating, and 
gynogenesis could therefore be useful as a means of accelerating the production of inbred fish. The degree of inbreeding would depend on the particular way in which diploidy arose. Thus retention of a first polar body would be equivalent to self-fertilisation (the highest natural form of inbreeding), regulation during cleavage would produce fully homozygous individuals, and retention of a second polar body would be intermediate between these two, depending on the extent of crossing-over during the reduction division of meiosis. It is therefore of great importance to determine the way in which diploid gynogenomes arise.

Parmenter (1933) concluded that diploidy in frog parthenogenesis could arise by more than one method, but that regulation during cleavage was the predominant mechanism, as indicated by delayed cleavage in most of the embryos destined to become viable diploids. This point was confirmed by Kawamura (1939) and proved beyond doubt by Subtelny's elegant demonstration (1958) of the production of diploid embryos from enucleated frog eggs by the introduction of haploid nuclei from androgenetic frog blastomeres. The lack of a specific cleavage delay in diploid gynogenesis in the present work and the absence of diploids amongst cold-shocked androgenetic embryos, however, suggests that regulation during cleavage does not explain diploid gynogenesis in fish.

The remaining possibilities of retention of a first or of a second polar body cannot be evaluated critically in the present experiments, although the first possibility seems very unlikely, because the first maturation division and extrusion of the first polar body occur long before the eggs are ripe and, to be able to re-establish diploidy by fusion with the egg pronucleus, the first polar body would itself need to undergo a prior mitotic division. In addition, the proximity of the daughter products of the second maturation division-even assuming that the first polar body divided-would make it much more likely that the egg pronucleus would fuse with its daughter product-the second polar body.

Diploid parthenogenesis has been recorded in turkeys (Olsen and Marsden, 1954; Olsen, 1960), and since only male offspring were observed (Poole and Olsen, 1957) it was concluded that diploidy did not arise by retention of a first polar body, the female being the heterogametic sex (XO) in turkeys. Further studies (Olsen, 1966) demonstrated that females heterozygous for a plumage colour gene produced parthenogenomes of both types of homozygote and one heterozygous individual, which was presumed to have arisen through crossing-over followed by fusion of the egg pronucleus and the second polar body. Similar studies with carp (Golovinskaia, 1968) also revealed segregation for a pair of alleles $(S s)$ determining scale pattern, but an independent second pair of alleles $(\mathcal{N} n)$, also determining scale patterns, did not segregate. It was concluded that diploidisation arose through retention of a second polar body and that the $\mathcal{N}$ locus which failed to segregate showed 100 per cent. crossing-over with the centromere. Retention of a first polar body cannot be excluded by these carp data, however, since the same results could be interpreted on this basis by assuming no crossing-over between $\mathcal{N}$ and the centromere and a high level of crossingover between $S$ and the centromere. Thus for any individual heterozygous for a gene $A$, with a cross-over frequency of $\alpha$, the genotypic frequencies after first polar body retention would be: $\left(1-\frac{1}{2} \alpha\right) A a ; \frac{1}{4} \alpha A A ; \frac{1}{4} \alpha a a$; and for retention of a second polar body, the frequencies would be: $\alpha A a ; \frac{1}{2}(1-\alpha)$ 
$A A ; \frac{1}{2}(1-\alpha)$ aa. To determine the type of diploidisation process by genetic means would require prior knowledge of the location of marker genes.

The viability of the gynogenetic plaice and trout in the present experiments was extremely low. Discounting the high mortality of haploids during embryonic growth, the mortality in diploids was most marked at or after hatching in plaice (fig. 4) and a similar effect was observed in trout, where only 35 alevins survived up to feeding from about 100 diploid hatching eggs. In addition, the surviving gynogenomes of both plaice and trout were not completely normal in appearance.

In almost all previous reports of artificial parthenogenesis or gynogenesis, the resultant individuals were also very inviable and were not completely normal compared with controls (Kawamura, 1939; Moriwaki, 1957; Subtelny, 1958; Golovinskaia, 1968).

In frogs, the low viability and high incidence of abnormalities in artificial parthenogenomes is consistent with their origin by duplication of a haploid genome, since this would produce complete homozygosity and the fullest possible manifestation of inbreeding depression. In fish, however, where diploidy is not restored during cleavage, segregation of chromosomes or crossing-over during meiosis I would reduce the degree of homozygosity.

For self-fertilisation, the coefficient of inbreeding, $F$, of an offspring, $X$, from a parent, $P$, is : $F x=\frac{1}{2}\left(1+F_{P}\right)$ (Falconer, 1964, chapter 3$)$. As already noted, gynogenesis by retention of a first polar body product would be equivalent to self-fertilisation, and for first generation offspring $\left(F_{P}=0\right)$ the coefficient of inbreeding would be 0.5 . For retention of a second polar body, $F_{P}$ will be equivalent to the degree of identity of daughter chromatids after meiosis $I$, i.e. equal to $1-\alpha$, where $\alpha$ is the overall cross-over frequency per chromosome. Thus for retention of a second polar body the coefficient of inbreeding for the first generation is: $F_{X}=\frac{1}{2}(2-\alpha)$.

Few data exist on crossing-over in fish, but what few there are suggest that cross-over frequencies are low. Thus in Lebistes reticulatus the maximum observed frequency for colour pattern genes was $0 \cdot 1$ (Winge and Ditlevsen, 1947), and in another cyprinodont fish, Xiphophorous maculatus, cross-over frequencies have been observed up to values of only 0.01 (Gordon, 1937; Kallman, 1965). Fish chromosome complements are usually made up of numerous small chromosomes and this would be consistent with low cross-over frequencies. Such low values would produce a very high coefficient of inbreeding in parthenogenesis or gynogenesis arising by retention of the second polar body. Thus if the mean cross-over frequency per chromosome was $0 \cdot 1$, the coefficient of inbreeding would be 0.95 and this is equivalent to about 14 generations of full sib-matings. In studies with Drosophila, Tantawy and Reeve (1956) observed little effect of inbreeding on survival and other characters up to theoretical $F$ values of about 0.5 , and marked reduction in survival occurred only after $F=0 \cdot 8$. The low levels of viability observed in gynogenetic plaice and trout in the present experiments, and in gynogenetic carp (Golovinskaia, 1968), can be explained on the basis of diploidisation by retention of a second polar body, together with a low incidence of crossingover in the developing oocyte.

Although attempts to rear gynogenetic fish failed in the present experiments, there appears to be no theoretical reason why this should not be accomplished with improved husbandry. Although normal development of 
inbred lines allows for slow natural selection of adapted genotypes, this should be compensated by the high fecundities of fish.

Fish cultivation lags behind other forms of animal husbandry in many ways but probably more so in the field of breeding than in any other respect. Potential short cuts to genetic analysis are therefore desirable, to produce the rapid progress which is necessary if fish cultivation is to approach the level of success achieved with modern breeding methods in other animals. In this respect, gynogenesis offers a rapid means of developing inbred material without the delay associated with normal systems of inbreeding.

\section{Summary}

1. Eggs of trout (Salmo trutta L.), plaice (Pleuronectes platessa L.) and flounder (Platichthys flesus L.) were successfully fertilised by spermatozoa exposed to cobalt-60 gamma ray doses of from $10^{4}$ to $10^{5}$ rad. Typical "Hertwig phenomena" were observed, with survival increasing with increasing dose, suggesting that the developing embryos at high radiation doses were gynogenetic.

2. Gynogenetic embryos were of two types, corresponding closely to haploid and diploid syndromes in parthenogenetic frogs. Haploidy of grossly abnormal trout gynogenomes and diploidy in near-normal gynogenomes were indicated by a comparison of nuclear sizes in late embryos.

3. Viability of diploid gynogenomes was very low and the individuals were not completely normal but showed many minor abnormalities comparable to inbreeding effects in laboratory fish.

4. The normal incidence of diploid as opposed to haploid gynogenesis was less than 1 per cent., but this could be increased to 60 per cent. or more by application of a cold shock 20 minutes after fertilisation. Cold shocks applied 40 minutes after fertilisation were not effective.

5. Cleavage times were similar for gynogenetic haploids, diploids and normal controls, and there was no evidence of delayed cleavage as in frog parthenogenesis.

6. Androgenesis in irradiated flounder eggs produced only haploid embryos, whether the eggs were cold-shocked or not.

7. It was concluded that diploid gynogenesis probably arises through fusion of a female pronucleus and the second polar body which, with a low cross-over frequency in fish oocytes, would explain the low viability of fish gynogenomes.

Acknowledgments. - I wish to thank Mr L. D. Peart of the Berkshire Trout Farm, Hungerford, for trout hatchery facilities, and Professor D. R. Davies of the University of East Anglia (formerly of the UKAEA) for making gamma irradiation facilities available.

\section{References}

BEATTY, R. A. 1964. Gynogenesis in vertebrates: fertilization by genetically inactivated spermatozoa. Proc. Int. Symp. on Effects of Ionizing Radiation on the Reproductive System, Fort Collins, Colorado, 1962 (eds. Carlson, W. D., and Gassner, F. X.), 229-238.

FAlConer, D. s. 1964. Introduction to quantitative genetics. Chapt. 3, pp. 47-67, Oliver and Boyd, Edinburgh and London.

FANKHAUSER, G. 1945. The effects of changes in chromosome number on amphibian development. Q. Rev. Biol., 20, 20-78. 
Golovinskaia, K. A. 1968. Genetics and selections of fish and artificial gynogenesis of the carp (Cyprinus carpio). FAO Fish Rep. No. 44, Vol. 4, Proc. World Symp. on warm water pond fish culture, Rome, 1966 (ed. Pillay, T. V. R.), 215-222.

GORDON, M. 1937. Genetics of Platypoecilus. III. Inheritance of sex and crossing-over of the sex chromosomes in the platy fish. Genetics, $\mathcal{N} . \Upsilon$., 22, 376-392.

Hertwig, O. 1911. Die Radiumkrankheit tierischer Keimzellen. Arch. Mikr. Anat., 77, $1-97$.

HUBBS, c. L., AND HUBBs, L. C. 1932. Apparent parthenogenesis in nature, in a form of fish of hybrid origin. Science, $\mathcal{N} . \Upsilon ., 76,628-630$.

Kallman, K. D. 1962. Gynogenesis in the teleost, Mollienesia formosa, (Girard), with a discussion of the detection of parthenogenesis in vertebrates by tissue transplantation. 7. Genet., 58, 7-24.

KALLMAN, K. D. 1965. Genetics and geography of sex determination in the poeciliid fish, Xiphophorous maculatus. Zoologica, N.Y., 50, 151-190.

KaWAMURA, T. 1939. Artificial parthenogenesis in the frog. I. Chromosome numbers and their relation to cleavage histories. F. Sci. Hiroshima Univ., Ser. B 1, 6, 115-1000.

MrYADA, s. 1960. Studies on haploid frogs. 7. Sci. Hiroshima Univ., Ser. B1, 19, 1-56.

MORIWAKI, T. 1957. Studies on matured parthenogenetic frogs. I. The development and the reproductive ability. 7. Sci. Hiroshima Univ., Ser. B1, 17, 13-32.

olsen, M. w. 1960. Nine year summary of parthenogenesis in turkeys. Proc. Soc. exp. Biol. and Med., 105, 279-281.

OLSEN, M. w. 1966. Segregation and replication of chromosomes in turkey parthenogenesis. Nature, Lond., 212, 435-436.

OLSEN, M. W., AND MARSDEN, s. J. 1954. Development in unfertile turkey eggs. J. exp. Zool., 126, 337-347.

PARMENTER, c. L. 1933. Haploid diploid triploid and tetraploid chromosome numbers and their origin in parthenogenetically developed larvae and frogs of Rana pipiens and Rana palustris. 7. exp. Zool., 66, 409-450.

POOLe, H. K., AND OlSEN, M. w. 1957. The sex of parthenogenetic turkey embryos. $\mathcal{J}$. Hered., 48, 217.

ROMASHOV, D. D., BELYAEVA, v. N., GOlOVinSKAIA, K. A., AND PROKOF'EVA-BEL'GOVSKAYA, A. A. 1961. Radiation disease in fish (In Russian). Radiatsionnaya Genetika, Acad. of Sciences USSR, Moscow, 1961, 247-266.

ROSTAND, J. 1934. Gynogenèse du crapaud par refroidissement de l'oeuf. C. r. Séane, Soc. Biol., 115, 1680-1681.

ROSTAND, J. 1936. Gynogenèse par refroidissement des oeufs chez Hyla arborea. C. $r$. Séane, Soc. Biol., 122, 1012-1013.

SUBTELNY, s. 1958. The development of haploid and homozygous diploid frog embryos obtained from transplantation of haploid nuclei. 7. exp. Zool., 139, 263-305.

TANTAWY, A. O., AND REEVE, E. C. R. 1956. Studies in quantitative inheritance. IX. The effects of inbreeding at different rates in Drosophila melanogaster. Z. VererbLehre, 87, 648-667.

TYLER, A. 1941. Artificial parthenogenesis. Biol. Rev., 16, 291-336.

WINGE, ø., AND DITLEVSEN, E. 1947. Colour inheritance and sex determination in Lebistes. Heredity, Lond., 1, 65-83. 

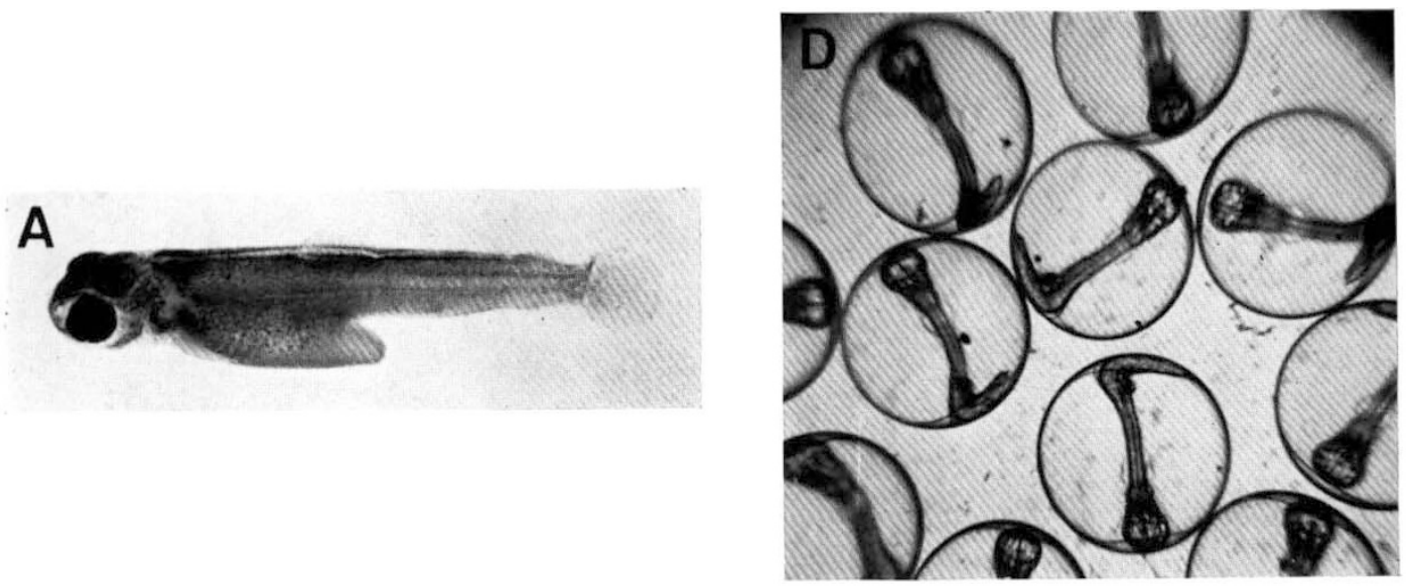

B
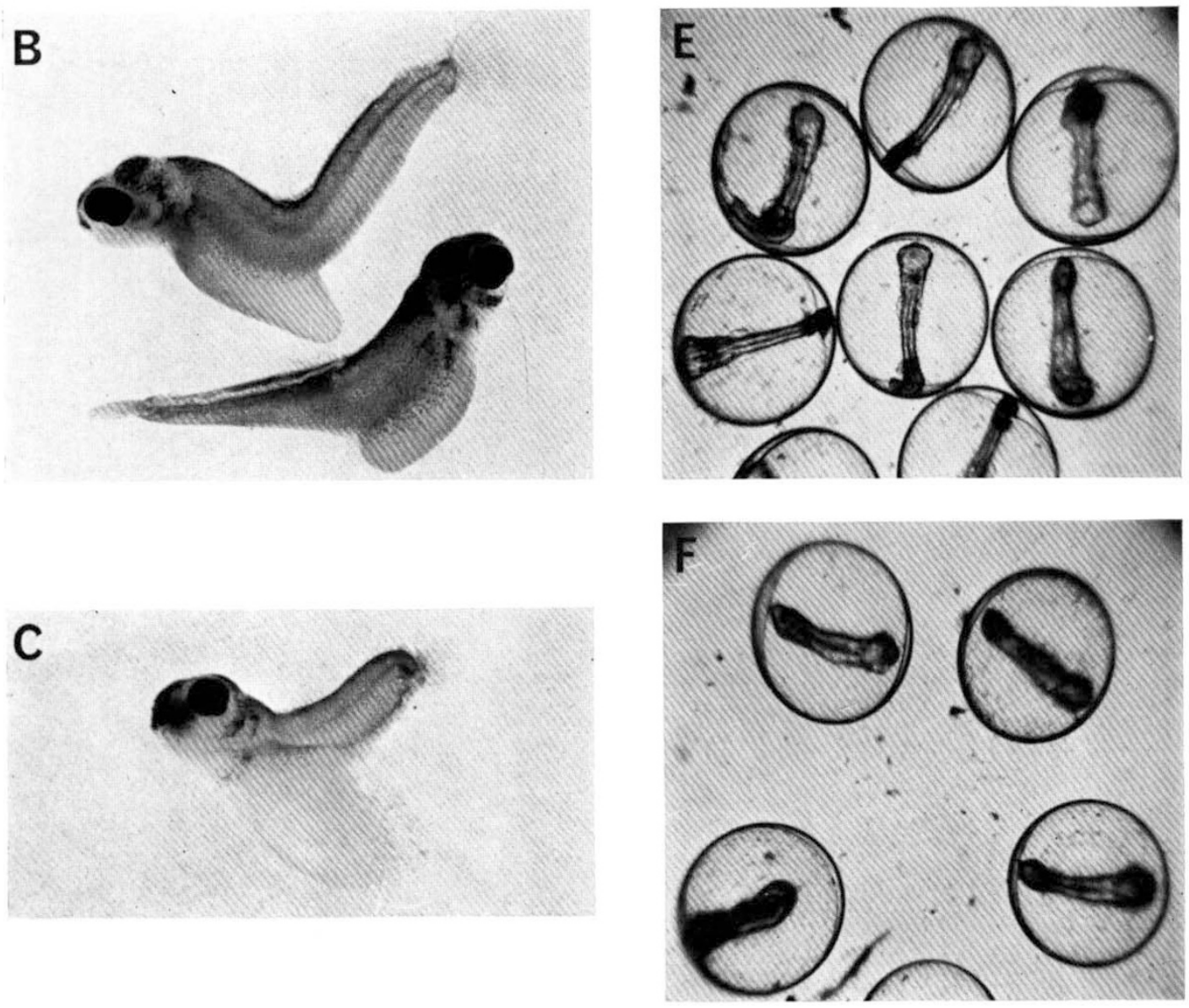

Left: Trout alevins 6 weeks after fertilisation. A, control; B, gynogenetic diploids; C, gynogenetic haploids $(\times 4)$.

Right: Plaice embryos 8 days after fertilisation. D, control; E, gynogenetic diploids; F, gynogenetic haploids $(\times 10)$. 